\title{
Electrodeposition of Aluminum on Cathodes in Ionic Liquid Based Choline Chloride/Urea/ALCL 3
}

\author{
Thanh-Cong Huynh ${ }^{1}$, Quang P. D. Dao ${ }^{1}$, Thanh-Ngoc Truong ${ }^{1}$, Ngoc-Giang Doan ${ }^{1} \&$ Son-Lam Ho ${ }^{1}$ \\ ${ }^{1}$ Institute of Applied Materials Science, Vietnam Academy of Science and Technology, Ho Chi Minh City, \\ Vietnam \\ Correspondence: Thanh-Cong Huynh, Institute of Applied Materials Science, Vietnam Academy of Science and \\ Technology, No 1, Mac Dinh Chi Street, District 1, Ho Chi Minh City, Vietnam. Tel: 84-9-3381-1662. E-mail: \\ htcong12345@gmail.com; htcong@iams.vast.vn
}

Received: June 21, 2014 Accepted: July 30, 2014 Online Published: September 24, 2014

doi:10.5539/ep.v3n4p59 URL: http://dx.doi.org/10.5539/ep.v3n4p59

\begin{abstract}
Electrodeposition of aluminum on metal at low temperatures, with the participation of the ionic liquid electrolyte will contribute to solving many technical issues in critical industries such as automobiles, aircraft, electronics ... the industry uses aluminum and aluminum coated materials most.Using ionic liquids based on choline chloride and urea to electrodeposition of aluminum is more published in scientific journals in the world. In this article, we present the preliminary results of electrodeposition of aluminum on cathodes as copper, iron and especially glassy carbon. The nature of electrolytes based on choline chloride and urea were analyzed and identified. The solubility of aluminum chloride in this mixture also surveyed. The results showed that only choline chloride mixture / urea with a mole ratio of 1:1 solution is to create transparent and recrystallized at room temperature. The nature of electrolytes based on choline chloride and urea were analyzed and identified. The solubility of aluminum chloride in this mixture also surveyed. The results showed that only choline chloride mixture / urea with a mole ratio of 1:1 solution is to create transparent and recrystallized at room temperature. Solubility of aluminum chloride in this system is $5 \%$ by weight. So in the study of aluminum deposited on the cathode, we use only liquid choline chloride / urea / $\mathrm{AlCl}_{3}$ at the rate of $1 \mathrm{~mol} / 1 \mathrm{~mol}+5 \%$ by weight of $\mathrm{AlCl}_{3}$. The electroplating are made with temperatures from $90-120^{\circ} \mathrm{C}$, the time is 2 hours. Distance between two poles is 2 $\mathrm{cm}$, the maximum of surface area $3 \mathrm{~cm}^{2}$ voltage between the two poles from 1-3 V and amperage stable at 100 $150 \mathrm{~mA}$. Nitrogen environment are set to limit the influence of oxygen and hydrogen. The results of the analysis on the cathode structure of aluminum films by XRD, SEM, XRF, EDS ... showed similarities with the aluminum anode. The purity of the aluminum film obtained depending on the materials used as the cathode. The purity of aluminum on the GC-cathode is $92.42 \%$ atom, on iron is $70.33 \%$ atom and on copper is $82.63 \%$ atom.
\end{abstract}

Keywords: electrodeposition, aluminum, deep eutectic solvent (DES), ionic liquid, conductivity

\section{Introduction}

Research using ionic liquids for electrodepositing of aluminum was Hurley FH and Wier TP, published in 1951 [Hurley F. H., Wier T. P.]. Accordingly, the authors have proposed the use of low-temperature molten salt, formed by the combination of aluminum chloride anhydrous salt with organic compounds such as 1-ethyl-3-methylimidazolium chloride [EMim] $\mathrm{Cl}$ as the electrolyte for aluminum electroplating process at low temperatures. Ionic liquids based on $\mathrm{AlCl}_{3}$, can be considered as the first generation of ionic liquids.

The ionic liquid has the advantage over the previous generation using ionic liquids as Tetrafluoroborate anion ${ }^{[\mathrm{BF} 4]^{-}}$or hexafluorophotphat $[\mathrm{PF} 6]^{-}$hydrophobic by nature and their stability. In addition, during electrodeposion do not appear toxic HF gas for environmental.

Over the past 10 years, the research in this direction is special attention. The difference is the use of ionic liquids recently quite diverse, such as EMIM [Tf2N]- $\mathrm{AlCl}_{3}$, Trimethylphenylammonium chloride (TMPAC), EMIM) $\mathrm{Br}$, [J. L. Solà Cervera and A. König, Liu Q. et al, Brown L., Li-peng Zhang et al, S. Zein El Abedin et al, F. Endres] or mixed system between 1-butyl-1-methylpyrrolidinium chloride/ $\mathrm{AlCl}_{3}$ and 1-ethyl-3-methylimidazolium chloride/ $\mathrm{AlCl}_{3}$ [Giridhar P. et al, S. Zein El Abedin et al]. 1-Butyl-1-sulfonate-ethylpyrrolidiniumtrifluoromethyl [Giridhar P. et al], piperidinum-Alkyl halides [Mandar S. Risbud et al], triethylamine hydrochloride [Suneesh P.V. et al]. 
In the early years of the 20-th century, a new ionic liquids based on mixtures of quaternary ammonium salt-(2-hydroxy-ethyl-trimethyl ammonium chloride) with a number of substances such as hydrogen bonding amide, glycol or acid carboxylic acid (mono-diacid) - to form a solvent capable of dissolving the metal salt and oxide, low cost and ease of recycled or biodegradable without causing pollution.

This new ionic liquids are called DES (deep eutectic solvent). The first publication of this ionic liquid system is of Abbott et al from 2001 to present. In some applications of DES, for electroplating applications are particularly interested in research, which plated silver, copper, zinc, nickel, chromium ... as well as their mixtures have been published in the past 5 years. The results of this study showed that ionic liquids DES system is not affected by air and humidity should stabilize in the electroplating process. In addition, the use of DES does not need to add the strong inorganic acids as the other ionic liquid system - factors affecting the environment. It can be seen that the potential of the use of DES in the metal electrodepositing are positive and some areas have been able to the industry. However, the use of DES for aluminum electrodepositing almost many unresolved issues, the number of related works have not been published, whether or not the works mentioned in the present.

The preliminary results of the study we aim to use DES for aluminum plating on the surface of various materials shown appearance aluminum layer structure similar to the structure of the aluminum anode.

\section{Experimental Methodology}

All the experimental works of this research were carried out in a natural environment of the laboratory except the electrodeposition process is performed in nitrogen atmosphere.

\subsection{Chemicals}

Choline chloride ( $p>99 \%$ ), urea (99.9\%), anhydrous aluminum chloride (99.99\%), were purchased from Merck (Germany). All used chemicals are of high purity (>99\%) which must be handled with care.

\subsection{Synthesis and Characterization of DESs}

The eutectic solvents formed by following the method previously described in many publications [15-30]. In this study, choline chloride and urea are mixed in a glass flask according to the molar ratio, respectively, 1: 1; 1: 2 and 2: 1 . The flask was mounted with a magnetic stirrer and heated by oil bath. Nitrogen is added to the flask to remove water vapor and air. Determine the temperature and the time is completely dissolved and the flask put out oil bath, retain nitrogen environment for at least 1 hour. Then, the mixture was dried overnight at $100{ }^{\circ} \mathrm{C}$ in a vacuum oven to obtain the final product and prior to the next experiment.

\subsection{Measurement of Solubility's and Physicochemical Properties of Electrolytes of AlCl3 in DES}

Measurement of the solubility of $\mathrm{AlCl}_{3}$ in the DES solution was performed by stirring $5 \%$ (each $0.015 \mathrm{~mol}$ ) of $\mathrm{AlCl}_{3}$ in $40 \mathrm{~g}$ of DES (each $0.2 \mathrm{~mol}$ ) and gradually increase the temperature until dissolved $\mathrm{AlCl}_{3}$ in DES. Let cool at room temperature and measuring the physical properties of electrolyst. Same as above with $\mathrm{AlCl}_{3}$ concentration of $10 \%, 15 \%$ and $20 \%$ (corresponding to $0.03 \mathrm{~mol}, 0.045 \mathrm{~mol}$ and $0.06 \mathrm{~mol} \mathrm{AlCl}_{3}$ )

\subsection{Study on Cyclic Voltammetry of Electrolyte}

In the determination of cyclic voltammograms were performed using an electrochemical workstation Potential Galvan stat ((PGS-10- Institute of chemistry of Vietnam academy of science and technology-VAST). Platinum working electrode and platinum plate counter electrode were used. A non-aqueous $\mathrm{Ag}+/ \mathrm{Ag}$ electrode, containing the 0.1 mol. $\mathrm{L}^{-1}$ solution of $\mathrm{AgNO}_{3}$ in $\mathrm{KCl}$ was employed as reference electrode (RE). As for the electrodeposition experiments, the working, counter and reference electrodes were iron, copper foil, and glassy carbon plate, respectively. Cyclic voltammograms are investigated with Choline Chloride - urea 1:1, and choline chloride / urea / $\mathrm{AlCl}_{3}$ at a temperature of $30^{\circ} \mathrm{C}$, amperage of $50 \mathrm{mV} / \mathrm{s}$.

\subsection{Electrodeposition of Aluminum on Cathode}

The electrodeposition experiments of aluminum on the surface of foil copper, iron foil and plate GC was conducted by galvannostatic method. Electrolyte (cholinechloride / urea / $\mathrm{AlCl}_{3}$ ) is heated by oil bath at a temperature of $80-95^{\circ} \mathrm{C}$, the electrical current is $80-95 \mathrm{~mA}$ and time was $2 \mathrm{~h}$. After electroplating, the cathode was washed with acetonitrile, deionized water and finally dried and determined the weight. Aluminum layer deposited on the cathode was analyzed and determined by methods such as XRD, EDS, SEM. 


\section{Results and Discussion}

\subsection{Synthesis and Characterization of DESs}

\subsubsection{Soluble Choline Chloride and Urea}

- Soluble Choline Chloride and Urea at the rate of $1: 1$ in mole ratio is at $60^{\circ} \mathrm{C}$ temperature, dissolved time of 5 minutes. The mixture was transparent and did not crystalized when cooled to room temperature.

- Soluble Choline Chloride and Urea at the rate of 2:1 in mole ratio is at $60{ }^{\circ} \mathrm{C}$ temperature, dissolved time of 5 minutes. The mixture was transparent and did not crystalized when cooled to room temperature.

- Soluble Choline Chloride and Urea at the rate of $1: 2$ in mole ratio is at a temperature of $75{ }^{\circ} \mathrm{C}$, time is 8 minutes completely dissolved. The mixture was transparent, and crystallized fastly when the temperature starts to decrease (less than $75^{\circ} \mathrm{C}$ temperature).

Table 1. Physical properties of the solution depends on the rate of choline chloride / urea

\begin{tabular}{cccccc}
\hline $\begin{array}{c}\text { Choline/urea } \\
(\mathrm{mol} / \mathrm{mol})\end{array}$ & $\mathrm{pH}$ & $\begin{array}{c}\text { Density } \\
(\mathrm{g} / \mathrm{ml})\end{array}$ & $\begin{array}{c}\text { Viscosity } \\
(\mathrm{cP})\end{array}$ & $\begin{array}{c}\text { Electrical conductivity } \\
(\mathrm{mS})\end{array}$ & $\begin{array}{c}\text { Water content } \\
(\mathrm{ppm})\end{array}$ \\
\hline $1: 1$ & 6.65 & 1.197 & 61.5 & 1.64 & 650 \\
$2: 1$ & 5.92 & 1.167 & 57.3 & 2.96 & 810 \\
$1: 2$ & - & - & - & - & - \\
\hline
\end{tabular}

Through the survey results of physical properties of the solution depends on the rate of choline chloride as table 1 , we chose the DES solution with a choline chloride / urea is 1:1 to carry out research steps next.

\subsubsection{Characterization of DES (1:1)}

${ }^{1} \mathrm{H}$ NMR $\left(\mathrm{CDCl}_{3}, 500 \mathrm{MHz}\right): 3.2(1 \mathrm{H}), 3.3(5 \mathrm{H}), 3.5(5 \mathrm{H}), 4.0(7 \mathrm{H}), 4.8(1 \mathrm{H}), 5.7(1 \mathrm{H}) .{ }^{13} \mathrm{C} \mathrm{NMR}\left(\mathrm{CDCl}_{3}\right.$, 125MHz): 48.1; 49.5; 67.0; 69.0; 163.5. IR: $3325 \mathrm{~cm}^{-1}(\mathrm{OH}) ; 3194 \mathrm{~cm}^{-1}$ (CH alkyl ); $2987 \mathrm{~cm}^{-1}$ (CH alkyl); 1607 $\mathrm{cm}^{-1}$ (C-C, C-N); $1438 \mathrm{~cm}^{-1}$ (CH alkyl deform); $629 \mathrm{~cm}^{-1}$ (C- Cl stretch); $\mathrm{pH}$ (6.65); Density(1.1971 (g/ml); Viscosity 61.5 (c P); Electrical conductivity $\left(1.64 \mathrm{mS}^{-1}\right)$; Water content $(0.065 \% \sim 650$ p.p.m)

\subsection{Measurement of Solubility's and Physicochemical Properties of $\mathrm{AlCl}_{3}$ in DES}

\subsubsection{Solubility}

$\mathrm{AlCl}_{3}(99.99 \%)$ was dissolved slowly in Choline Chloride/Urea with stirring at room temperature in a glove box under nitrogen atmosphere and heated to complete dissolution. Fig u re $1(\mathrm{a}, \mathrm{b}, \mathrm{c})$ are pictures sowed solution after dissolving $\mathrm{AlCl}_{3}$ in DES (1:1) 24 hours and let cool at room temperature.

\section{Choline chloride 1:1 + $5 \% \mathrm{AlCl}_{3}$ solution:}

after dissolving milky-colored liquid, allow to cool at room temperature after 24 hours with no salt crystallization, the solution remains opaque white (Figure $1 \mathrm{a}$ ).

\section{Choline chloride 1:1 + $10 \% \mathrm{AlCl}_{3}$ solution}

after dissolving milky-colored liquid, allow to cool at room temperature after 24 hours with no salt crystallization, the solution remains opaque white (Figure 1b).

\section{Choline chloride 1:1 + $10 \% \mathrm{AlCl}_{3}$ solution}

Salt $\mathrm{AlCl}_{3}$ start fading into Cho-urea solution (1:1) at temperatures up to $120^{\circ} \mathrm{C}$ still not completely dissolved salt, heated to $140^{\circ} \mathrm{C}$ continue to remain undissolved salt added. Let cool at room temperature after 24 hours, the mixture separated layers (Figure 1c). 


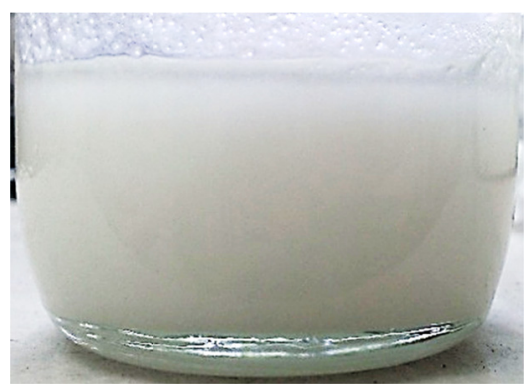

a. $5 \% \mathrm{AlCl}_{3}$

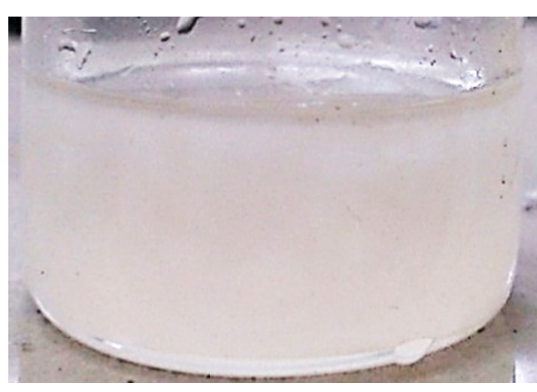

b. $10 \% \mathrm{AlCl}_{3}$

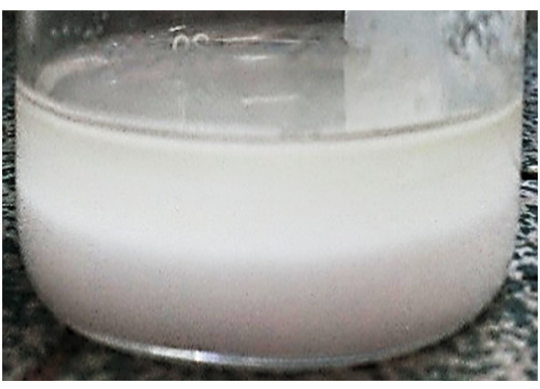

c. $15 \% \mathrm{AlCl}_{3}$

Figure1. Electrolyte solution after dissolving $\mathrm{AlCl}_{3}$ in $\mathrm{DES}(1: 1) 24$ hours and at room temperature

3.2.2 Physicochemical properties of electrolytes (DES (1:1) $+\mathrm{AlCl}_{3}$

Table 2. Physical properties of liquid choline chloride / urea (1:1) depends on the concentration of $\mathrm{AlCl}_{3}$ at $30{ }^{\circ} \mathrm{C}$

\begin{tabular}{cccccc}
\hline $\begin{array}{c}\text { Choline/urea }(1: 1) \\
+\mathrm{x} \% \mathrm{AlCl}_{3}\end{array}$ & $\mathrm{pH}$ & $\begin{array}{c}\text { Density } \\
(\mathrm{g} / \mathrm{ml})\end{array}$ & $\begin{array}{c}\text { Viscosity } \\
(\mathrm{cP})\end{array}$ & $\begin{array}{c}\text { Electrical conductivity } \\
(\mathrm{mS})\end{array}$ & $\begin{array}{c}\text { Water content } \\
(\mathrm{ppm})\end{array}$ \\
\hline 5 & 4.30 & 1.2286 & 109.1 & 1.56 & 950 \\
10 & 3.18 & 1.2647 & 473.1 & 1.17 & - \\
15 & - & - & - & - & - \\
\hline
\end{tabular}

Through the survey results of physical properties of the solution depends on the ratio of $\mathrm{AlCl}_{3}$ as in table. We chose DES $+5 \% \mathrm{AlCl}_{3}$ solution to carry out the next research steps.

\subsection{Study on Electrochemical of DES (1:1) and DES (1:1) $+5 \% \mathrm{AlCl}_{3}$}

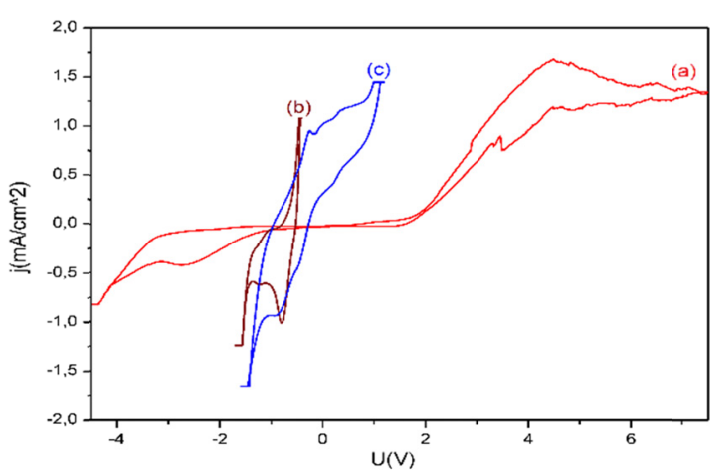

Figure 2. Cycle voltammograms of working electrode (WE): (a) glassy carbon; (b) Copper;

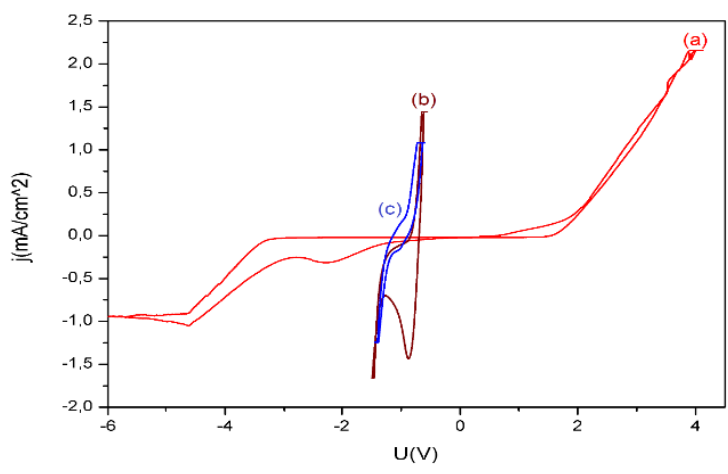

Figure 3. Cycle voltammograms of working electrode (WE): (a) glassy carbon; (b) Copper; (c)

In Figure 2, Cycle Voltammograms on the working electrode (WE) of the electrolyte without the presence $\mathrm{AlCl}_{3}$ differ quite clear:

For GC working electrode is an increase in the slope-to-3 V $4 \mathrm{~V}, 2 \mathrm{~V}$ and stability to. Then there is a steep increase at $4.5 \mathrm{~V}$ and $7 \mathrm{~V}$ descending to the ring back and closed at $1.5 \mathrm{~V}$ to $-1 \mathrm{~V}$. Limit in cathode located from $-2 \mathrm{~V}$ and in the anode is limited at $+2 \mathrm{~V}$, resulting ECW is $4 \mathrm{~V}$.

For the copper working electrode, the cathode is limited to $-1.4 \mathrm{~V}$ and $-0.6 \mathrm{~V}$ is anode limited. Since it is only 0.8 $\mathrm{V}$ ECW. Meanwhile, the WE cathode is limited only Iron $-1 \mathrm{~V}$ and anode is limited to $-0.2 \mathrm{~V}$, resulting in only a $0.8 \mathrm{~V}$ ECW (Table 2). 
Table 3. ECW of solution Choline Chloride - Urea (Molar ratio 1:1)

\begin{tabular}{lccc}
\hline \multicolumn{1}{c}{ Working cathode (WE) } & Cathode limit & Anodic limit & ECW \\
\hline Glassy Carbon & $-2 \mathrm{~V}$ & $2 \mathrm{~V}$ & $4 \mathrm{~V}$ \\
Copper $(\mathrm{Cu})$ & $-1.4 \mathrm{~V}$ & $-0.6 \mathrm{~V}$ & $0.8 \mathrm{~V}$ \\
Iron $(\mathrm{Fe})$ & $-1 \mathrm{~V}$ & $-0.2 \mathrm{~V}$ & $0.8 \mathrm{~V}$ \\
\hline
\end{tabular}

When the presence of $\mathrm{AlCl}$, Cycle voltammograms picture on the working electrode ( WE ) of electrolyte changes considerably better for GC, worse for cupper and iron ( figure 3 ).

While limits of GC cathode pulled down to $-3.5 \mathrm{~V}$, the limit of copper cathode and iron only $-0.43 \mathrm{~V}$ and -0.875 $\mathrm{V}$, respectively. On the other side, the anode limit of the GC reduced at $2 \mathrm{~V}$ compared with $1.5 \mathrm{~V}$ and of Iron from $-0.2 \mathrm{~V}$ to $-0.625 \mathrm{~V}$, respectively. Meanwhile, copper for $\mathrm{WE}$ is occurring phenomenon increased from -0.6 $\mathrm{V}$ to $-0.42 \mathrm{~V}$. The results of electrolyte $\mathrm{ECW}$ on making the presence of $5 \% \mathrm{AlCl}_{3}$ increased from $4 \mathrm{~V}$ to $5 \mathrm{~V}$ for the $\mathrm{GC}$, was reduced from $0.8 \mathrm{~V}$ to $0.1 \mathrm{~V}$ for copper and from $0.8 \mathrm{~V}$ to $0.1 \mathrm{~V}$ for iron (Table 4 ).

Table 4. ECW of solution Choline Chloride - Urea (Molar ratio 1:1) with $5 \% \mathrm{AlCl}_{3}$

\begin{tabular}{lccc}
\hline \multicolumn{1}{c}{ Working cathode $(\mathrm{WE})$} & Cathode limit & Anodic limit & ECW \\
\hline Glassy Carbon & $-3.5 \mathrm{~V}$ & $1.5 \mathrm{~V}$ & $5 \mathrm{~V}$ \\
Copper $(\mathrm{Cu})$ & $-0.43 \mathrm{~V}$ & $-0.42 \mathrm{~V}$ & $0.1 \mathrm{~V}$ \\
Iron $(\mathrm{Fe})$ & $-0.875 \mathrm{~V}$ & $-0.625 \mathrm{~V}$ & $0.3 \mathrm{~V}$ \\
\hline
\end{tabular}

The results showed that, for choline chloride electrolyte / urea 1:1 +5\% $\mathrm{AlCl}_{3}$ can be used for electro-deposition of alumina on the aforementioned electrodes with very little amperage. This is consistent with some previous studies for other ionic liquids. Osteryoung and Welch proved that the aluminum deposition process can be reversed (in an ionic liquid butylpyridinium chloride $/ \mathrm{AlCl}_{3}$ ) [31]. Deposition occurred at $-0.43 \mathrm{~V}$ and oxidation was observed at $-0.22 \mathrm{~V}$. Lay and Skyllas-Kazacos [32] studied the electrodeposition of aluminum on GC electrode in liquid imidazolium with tetrachloroaluminate at $-0.2 \mathrm{~V}$. The same phenomenon also on the iron electrode was observed at $0.2 \mathrm{~V}$.

\subsection{Electrodeposition of Aluminum on Cathode}

Aluminum electro-deposition process was carried out in equipment as described in section 2.5. Some technical indicators of the experiment are shown in Table 5 below.

Table 5. The data of electro-deposition aluminum process on the different electrodes

\begin{tabular}{cccccccc}
\hline STT & Cathode & $\begin{array}{c}\text { Voltage } \\
(\mathrm{V})\end{array}$ & $\begin{array}{c}\text { Temperature } \\
\left({ }^{\circ} \mathrm{C}\right)\end{array}$ & $\begin{array}{c}\text { Area } \\
\text { electrodes } \\
\left(\mathrm{cm}^{2}\right)\end{array}$ & $\begin{array}{c}\text { The distance between } \\
\text { the cathode and anode } \\
(\mathrm{cm})\end{array}$ & $\begin{array}{c}\text { Current } \\
(\mathrm{m} \mathrm{A})\end{array}$ & Time (h) \\
\hline 1 & $\mathrm{GC}$ & -2 & $80-95$ & 3 & 2.5 & $80-95$ & 2 \\
2 & $\mathrm{Cu}$ & -1.5 & $80-95$ & 3 & 2.5 & $80-95$ & 2 \\
3 & $\mathrm{Fe}$ & -1 & $80-95$ & 3 & 2.5 & $80-95$ & 2 \\
\hline
\end{tabular}

The previous study showed that the electro-deposition of $\mathrm{Al}$ can only be done in an electrolyte solution is acidic, which causes ion $\mathrm{Al}_{2} \mathrm{Cl}_{7}$-reduction arising aluminum $\left(\mathrm{Al}^{+3}\right)$ to convert the aluminum surface cathode side, after receiving 3 electrons:

$$
4 \mathrm{Al}_{2} \mathrm{Cl}_{7}{ }^{-}+3 \mathrm{e}^{-} \rightarrow \mathrm{Al}+7 \mathrm{AlCl}_{4}{ }^{-}
$$

Also, aluminum oxide can form on the surface of the cathode, where the presence of oxygen or water. This suspicion can be removed because of the water content in the electrolyte solution our very low (Table 2) and nitrogen gas was bubbled directly into the solution during electroplating. The EDS analysis results can indicate the following things. 
Based on the weight change of the anode (aluminum) conducted before and after electrodepositing, may determine the amount of aluminum is lost from the anode. Similarly can determine the weight of aluminum deposited on the cathode surface. The experimental results are shown in Table 6 and digital picture of the cathode is shown in Figure 7.

Table 6. Results aluminum electro-deposition on the cathode

\begin{tabular}{lcccccc}
\hline \multirow{2}{*}{$\begin{array}{c}\text { The weight of the } \\
\text { Anode and Cathode }\end{array}$} & \multicolumn{2}{c}{ Experiment 1 } & \multicolumn{2}{c}{ Experiment 2 } & \multicolumn{2}{c}{ Experiment 3 } \\
\cline { 2 - 7 } & Al-anode & GC-cathode & Al-Anode & Fe-Cathode & Al-Anode & Cu-Cathode \\
\hline The weight before EP & 6.1022 & 4.2980 & 6.0012 & 22.5643 & 6.0342 & 32.3573 \\
The weight after EP & 5.7610 & 4.4032 & 5.6332 & 22.8015 & 5.6774 & 32.4614 \\
Weight differences & 0.3412 & 0.1052 & 0.3680 & 0,2372 & 0.3568 & 0.1041 \\
\% Al-coated on cathode & & 30.83 & & 64.45 & & 29.17 \\
\hline
\end{tabular}

Results in Table 6 show that the mass loss of aluminum from the anode approximately equal for all three experiments and accounted for about 5.6 to $6 \%$ by weight of anodes. Meanwhile, the amount of aluminum coated on the cathode there is a difference: for iron cathode, aluminum coated over $60 \%$, while for the GC and copper cathode, aluminum coated only at $30 \%$. While that digital camera pictures of surface cathodes in Figure 7 shows the surface of copper and GC cathodes are smooth and finely than the iron cathode surface.

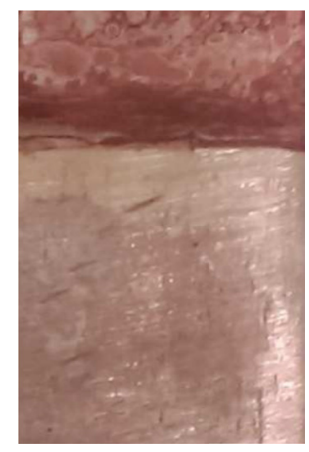

a. Copper

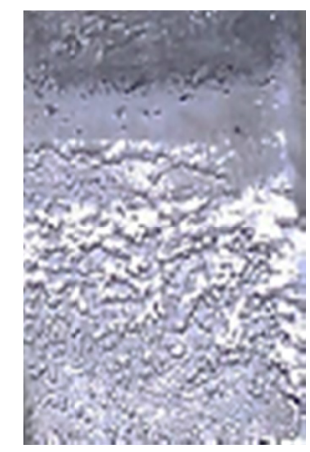

b. Ferrite

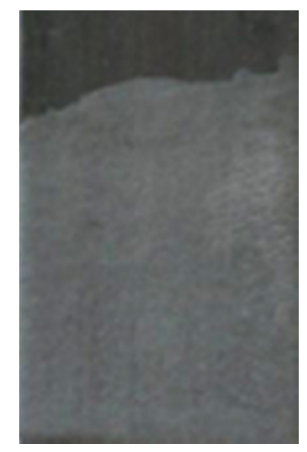

c. Glassy Carbon

Figure 4. Digital pictures of cathodes plated.

One of the reasons for the deposited aluminum layer is not glossy and smooth, can be deposited by aluminum impurities. This result was verified by EDS analysis following.

\subsection{Analysis and Characterization of Aluminum Coatings}

\subsubsection{Energy Dispersive X-ray Analytics (EDS)}

The analytical results Energy dispersive X-ray Analytics (EDS) component of aluminum coated on the surface of the cathode is made on equipment JEOL JED 2300 in accordance with analytical methods on the device Spectro's XRF analyzers from AMETEK Materials Analysis Division. On the figure 5, 6 and 7 are EDS spectrum of the aluminum layer is coated on the cathode. 

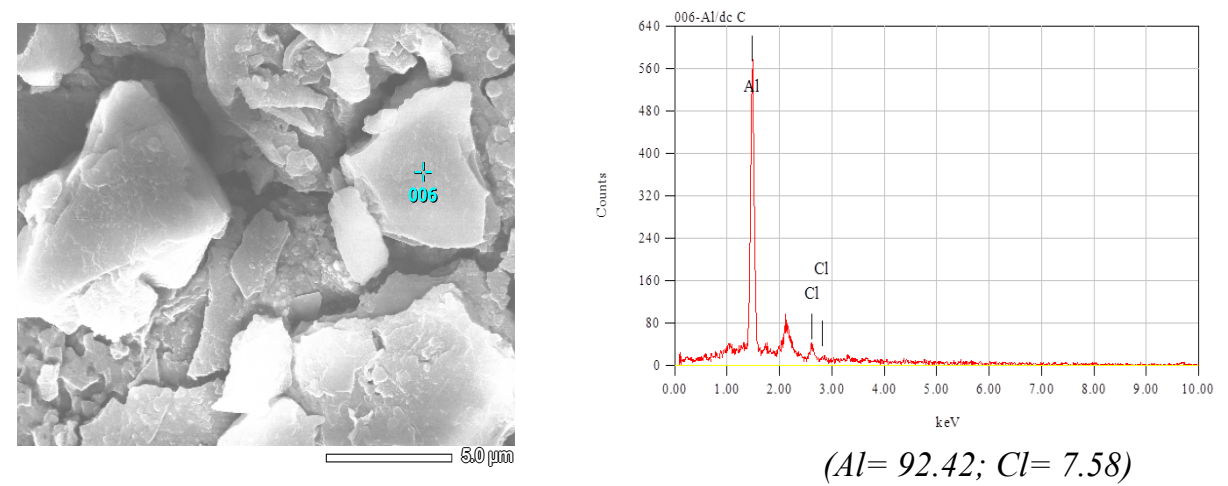

Figure 5. EDS spectrum of the Al-electrodeposit on GC cathode
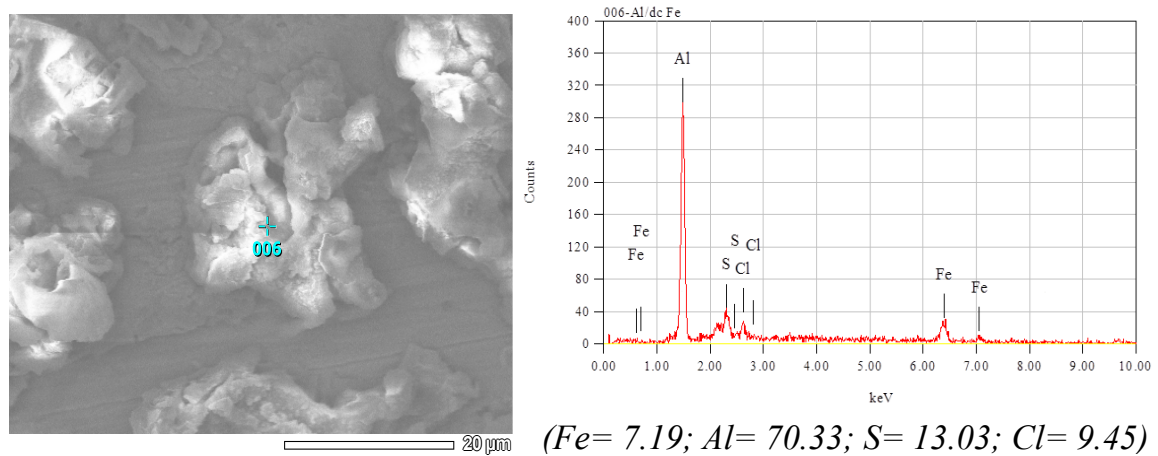

Figure 6. Aluminum coated on Fe electrode
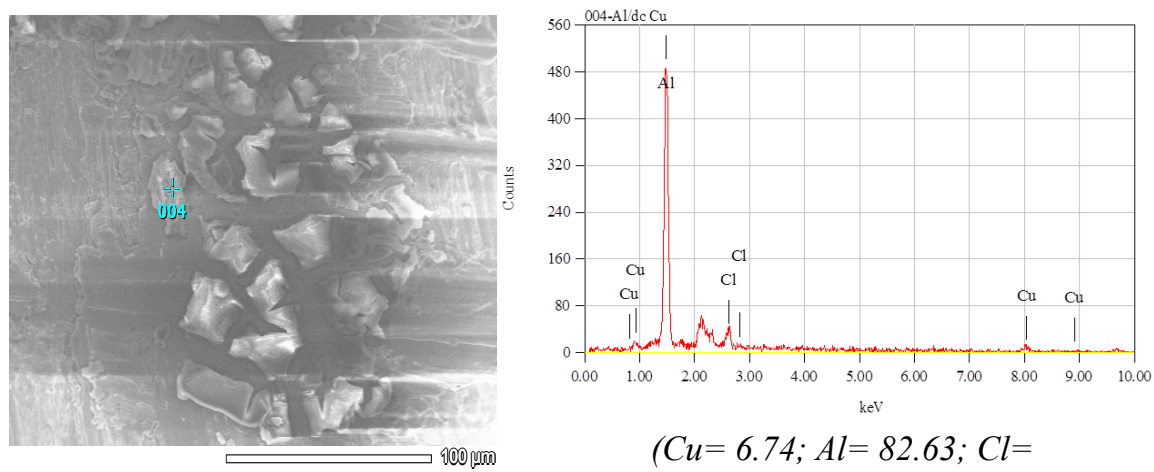

$(C u=6.74 ; A l=82.63 ; C l=$

Figure 7. Aluminum coated on $\mathrm{Cu}$ electrode

Table 7. Component elements exist in aluminum deposited layers on three cathode

\begin{tabular}{lcccc}
\hline $\begin{array}{c}\text { Cathodes } \\
\text { Element }\end{array}$ & GC & Fe & Cu \\
& Mass - $\%$ & Mass - $\%$ & Mass- \% \\
\hline $\mathrm{Al}$ & 92.42 & 70.33 & 82.63 \\
$\mathrm{Cl}$ & 7.58 & 9.45 & 10.63 \\
$\mathrm{Fe}$ & - & 7.19 & - \\
$\mathrm{S}$ & - & 13.03 & - \\
$\mathrm{Cu}$ & - & - & 6.74 \\
Total & 100.00 & 100.00 & 100.00 \\
\hline
\end{tabular}

The spectrum showed the highest peak of aluminum and clear. On the cathode surface is GC, because no other metals to purity of the aluminum coating can reach $92 \%$. For iron and copper cathode, these metals covered a part of aluminum layer, should result is decreased purity of aluminum. In addition, we also found a number of 
chlorine are present on all three cathode, it is possible contamination of $\mathrm{AlCl}_{3}$ on the cathode surface. The presence of sulfur on the cathode made of iron, iron sulfate can be formed in stages cathode surface cleaning with dilute sulfuric acid solution. Sum up results of identified elements exist on the aluminum cathode layer are shown in Table 7.

\subsubsection{X-ray Diffraction (XRD)}

XRD patterns of aluminum deposits were collected on X-ray diffractometer Bruker D8 Advance and the acquired diffraction pattern of the obtained sample shows only the pattern of aluminum metal (Figure 8). The diffraction peaks attributed to pure Al with a face-centered cubic structure (fcc) were clearly detected from the sample of electrodeposited aluminum layer on $\mathrm{Cu}$ cathode. Similar results were observed for other samples of aluminum on GC and Fe cathode.

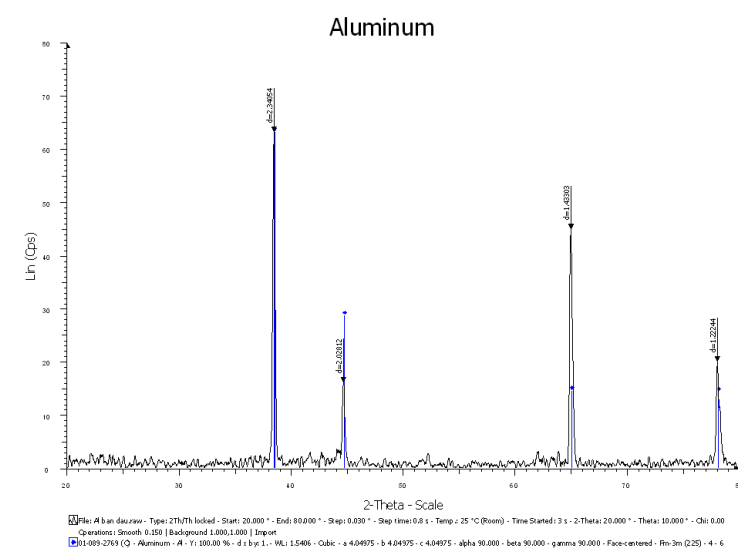

a. Al-Anode

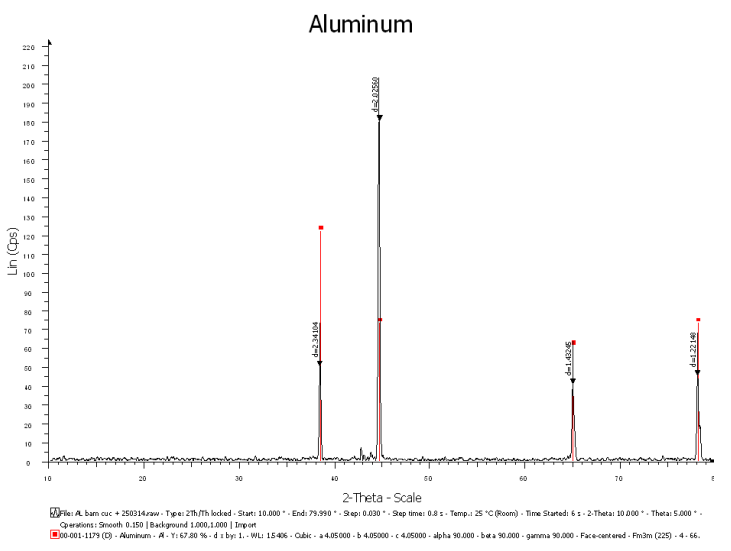

b. Al in aluminum layer on cathode

Figure 8. XRD pattern of the Al anode and Aluminum electrodeposit on copper cathode

\subsubsection{Scanning Electron Microscope (SEM)}

SEM was measured on Ultra-high Resolution Scanning Electron Microscope S-4800 (HITACHI). In Figure 9a is SEM image of cathode copper, taken at 20 micron. Although it has been carefully cleaned but still see the lines on the surface. In Figure 9b is the SEM image of copper cathode taken at $300 \mathrm{~nm}$. Figure 9c shows the aluminum anode surface taken at $300 \mathrm{~nm}$. There the similarity of the surface entirely made of aluminum catode (9b) with aluminum layer deposited on a copper cathode (9e-300nm). Figure 9d show aluminum layer deposited on the copper cathode, taken at 20 micron. 


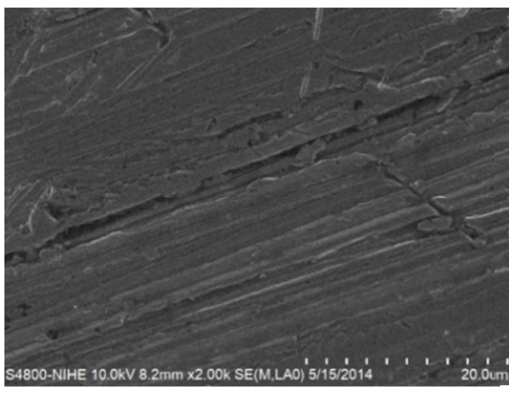

a. SEM of Copper cathode $20 \mu \mathrm{m}$

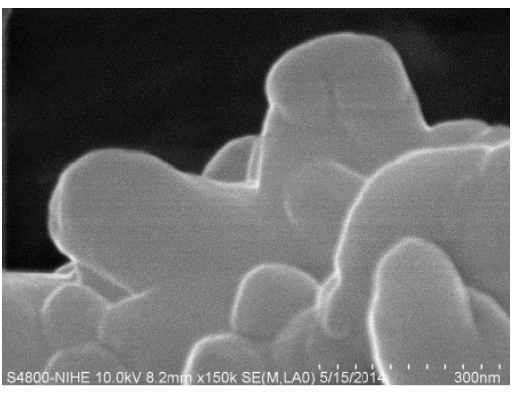

b. SEM of Copper cathode 300nm

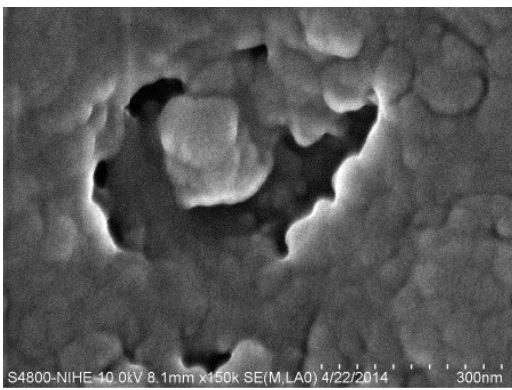

c. SEM of Aluminum Anode $300 \mathrm{~nm}$

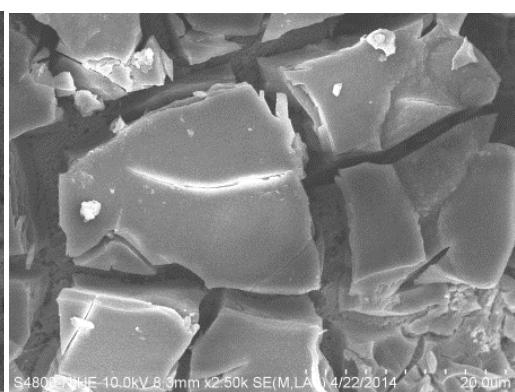

d. SEM of Aluminum layer on cathode $20 \mu \mathrm{m}$

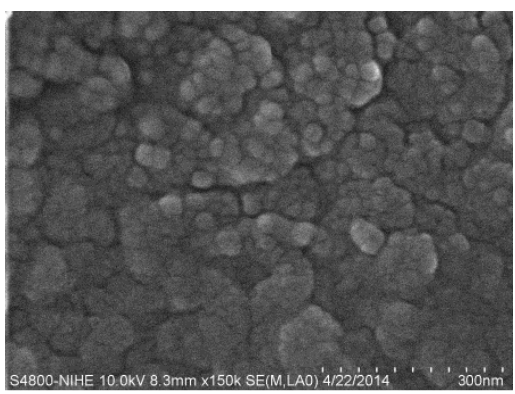

e. SEM of Aluminum layer on cathode $300 \mathrm{~nm}$

Figure 9. SEM images of copper cathodes surfaces (a) and aluminum layer on cathode (b)

\section{Conclusions}

From the experimental results mentioned above, one can draw the following conclusions:

(1) Electrolyte system can use chlroride choline / urea (1:1) with $5 \% \mathrm{AlCl}_{3}$ to perform electrodeposition on aluminum cathode copper, iron and $\mathrm{GC}$ at temperatures between $80-95^{\circ} \mathrm{C}$ with voltage from -1 to -2 depending on the cathode material and amperage stable at $80-95 \mathrm{~mA}$ in 2 hours.

(2) The amount of aluminum transferred from the anode to the cathode depends on the cathode material, and achieved $30.8 \%$ for GC; $64.45 \%$ for Fe and $29 \%$ for copper. Purity of aluminum on the cathode varied from $92.42 \%$ for GC, $70.33 \%$ for $\mathrm{Fe}$ and $82.63 \%$ for Copper. Need for further research to improve the purity of the aluminum on the cathode.

\section{Acknowledgements}

The authors gratefully acknowledge the financial support of the Vietnam Academy of science and technology through Research Program of Materials Science VAST 03.07/13-14

\section{References}

Abbott, A. P., Barron, J. C., Frisch, G., Ryder, K. S., \& Silva, A. F. (2011). The effect of additives on zinc electrodeposition from deep eutectic solvents. Electrochim. Acta, 56(14), 5272-5279. http://dx.doi.org/10.1016/j.electacta.2011.02.095

Abbott, A. P., Capper, G., Davies, D. L., McKenzie, K. J., \& Obi, S. U. (2005). Solubility of Metal Oxides in Deep Eutectic Solvents Based on Choline Chloride. J. Chem. Eng, 51, 1280-1282. http://dx.doi.org/10.1021/je060038c

Abbott, A. P., Capper, G., McKenzie, K. J., Glidle, A., \& Ryder, K. S. (2006). Electropolishing of stainless steels in a choline chloride based ionic liquid: an electrochemical study with surface characterisation using SEM and atomic force microscopy. Phys. Chem. Chem. Phys, 8, 4214-4221. http://dx.doi.org/10.1039/B607763N

Abbott, A. P., Nandhra, S., Postlethwaite, S., Smith, E. L., \& Ryder, K. S. (2007). Electroless deposition of metallic silver from a choline chloride-based ionic liquid: a study using acoustic impedance spectroscopy, SEM and atomic force microscopy. Phys. Chem. Chem. Phys., 9, 3735-3743. http://dx.doi.org/10.1039/B703954A 
Abbott, A. P., Ttaib, K. E., Frisch, G., McKenzie, K. J., \& Ryder, K. S. (2009). Electrodeposition of copper composites from deep eutectic solvents based on choline chloride. Phys. Chem. Chem. Phys, 11, 4269-4277. http://dx.doi.org/10.1039/B817881J

Abbott, A. P., Ttaib, K. E., Frisch, G., McKenzie, K. J., \& Ryder, K. S. (2012). The electrodeposition of silver composites using deep eutectic solvents. Phys Chem Chem Phys, 14(7), 2443-2449. http://dx.doi.org/10.1039/c2cp23712a

Abedin, S. Z, \& Endres, F. (2012), Free-standing aluminium nanowire architectures made in an ionic liquid. Chem. Phys. Chem, 226, 250-255. http://dx.doi.org/10.1002/cphc.201100639

Abedin, S. Z., Pulletikurthi, G., Schwab, P., \& Endres, F. (2010), Electrodeposition of nanocrystalline aluminium from chloroaluminate ionic liquid. Electrochemistry Communications, 12(8), 1084-1086. http://dx.doi.org/10.1016/j.elecom.2010.05.034

Anicai, L., Florea, A., \& Visa, T. (2011), Studies Regarding the Nickel electrodeposition from Choline Chloride Based Ionic Liquids. In S. Handy (Ed.), Applications of Ionic Liquids in Science and Technology. http://dx.doi.org/10.5772/23676

Brown, L. (2010). Electroplating with non-aqueous solutions. Trans. Inst. Met. Finish, 88, 122-123. http://dx.doi.org/10.1179/174591910x12729686675914

Cervera, J. L. S., \& König, A. (2010), Recycling Concept for Aluminum Electrodeposition from the Ionic Liquid System EMIM[Tf $\left.\mathrm{N}_{2}\right]-\mathrm{AlCl}_{3}$. Chemical Engineering \& Technology, 33(12), 1979-1988. http://dx.doi.org/10.1002/ceat.201000200

Ciocirlan, O., Iulian, O., \& Croitoru, O. (2010), Effect of Temperature on the Physico-chemical Properties of Three Ionic Liquids Containing Choline Chloride. REV. CHIM, 61, 721-723. Retrieved from http://www.revistadechimie.ro/pdf/CIOCARLAN\%20O.pdf\%208\%2010.pdf

Damiano, B. T., Shenenberger, A., Wixtrom, A. I., \& Fahttah, T. M. A. (2013). Electrochemical Deposition of Cobalt onto the Surface of Copper Using a Choline Chloride-Based Ionic Liquid Electrodeposition in Molten Salts and Ionic Liquids. ECS Trans, 50(11), 277-281. http://dx.doi.org /10.1149/05011.0277ecst

Durand, E., Lecomte, J., \& Villeneuve, P. (2013). Deep eutectic solvents: Synthesis, application, and focus on lipase-catalyzed reactions. Eur. J.Lipid Sci. Technol, 115, 379-385. http://dx.doi.org/10.1002/ejlt.201200416

Endres, F. (2011). Ionic Liquids for Electrochemical Deposition: Prospects and Challenges. Chemie Ingenieur Technik, 83, 1485-1492. http://dx.doi.org/10.1002/cite.201100038

Florea, A., Petica, A., Anicai, L., \& Visan, T. (2010). Preliminary studies of silver coatings formation from choline chloride based ionic liquids. U.P.B. Sci. Bull., Series B, 72(2), 115-126.

Giridhar, P., Abedin, S. Z, \& Endres, F. (2012). Electrodeposiotion of nanocrystalline Aluminium, Copper and Copper-Aluminium alloys from 1-Butyl-1-methylpyrrolidinium trifluoromethylsulfonate ionc liquid. Journal of Solid State Electrochemistry, 16, 3487-3497. http://dx.doi.org/10.1007/s10008-012-1800-x

Giridhar, P., Abedin, S. Z., \& Endres, F. (2012). Electrodeposition of aluminium from 1-butyl-1-methylpyrrolidinium chloride/ $\mathrm{AlCl}_{3}$ and mixtures with 1-ethyl-3-methylimidazolium chloride/AlCl 3 . Electrochim. Acta, 70, 210-214. http://dx.doi.org/10.1016/j.electacta.2012.03.056

Giridhar, P., Abedin, S. Z., \& Endres, F. (2012). Electrodeposition of aluminium from 1-butyl-1-methylpyrrolidinium chloride/AlCl3 and mixtures with 1-ethyl-3-methylimidazolium chloride/AlCl3. Electrochimica Acta, 70, 210-214. http://dx.doi.org/10.1016/j.electacta.2012.03.056

Golgovici, F. (2011). Cathodic Deposition of Pb from Ionic Liquids Based on Choline Chloride. Chem. Bull. "POLITEHNICA" Univ.Timisoara, 56(70), 62-66.

Golgovici, F., Visan, T. (2012). Electrodeposition behaviour of cadmium telluride from choline chloride-urea ionic liquids. Chalcogenide Letters, 9, $165-174$.

Hurley, F. H., \& Wier, T. P. (1951). The electrodeposition of aluminum from nonaqueous solution at room temperature. J. Electrochem. Soc., 98, 207-212. http://dx.doi.org/10.1149/1.2778133

Lai, P. K., \& Skyllas-Kazacos, M. (1988). Electrodeposition of aluminium in aluminium chloride/1-methyl-3-ethylimidazolium chloride, J. Electroanal. Chem., 248, 431-440. http://dx.doi.org/10.1016/0022-0728(88)85103-9 
Leron, R. B., \& Lee, M. H. (2012). Molar heat capacities of choline chloride-based deep eutectic solvents and their binary mixtures with water. Thermochim. Acta, 530, 52-57. http://dx.doi.org/10.1016/j.tca.2011.11.036

Liu, Q., Liu, K., Han, Q., \& Tu, G. (2010). Study on electrodeposition of Al from trimethylphenylammonium chloride (TMPAC)-aluminum chloride $\left(\mathrm{AlCl}_{3}\right)$ ionic liquids - benzene. Chin. Surf. Eng., 23, 34-39.

Risbud, M. S., Kononov, R., Bucknall, M., Barry J., Welch, John F. McCann, Maria \& Skyllas-Kazacos, M. S. (2012). Anodic and cathodic processes in piperidinium- based ionic liquid mixtures with $\mathrm{AlCl}_{3}$. Eur. Chem. Bull., 1(10), 422-433.

Suneesh, P. V., Satheesh Babu, T. G., \& Ramachandran, T. (2013). Electrodeposition of aluminium and aluminium-copper alloys from a room temperature ionic liquid electrolyte containing aluminium chloride and triethylamine hydrochloride. International Journal of Minerals, Metallurgy, and Materials, 20(90), 909-916. http://dx.doi.org/10.1007/s12613-013-0814-4

Tsuda, B., \& Kuwabata, H. (2010). Electrochemistry of Copper (I) Oxide in the 66.7-33.3 mol \% Urea-Choline Chloride Room-Temperature Eutectic Melt. Journal of the Electrochemical Society, 157(8), 96-103. http://dx.doi.org/10.1149/1.3377117

Vijayakumar, J., Mohan, S., Kumar, S.A., Suseendiran, S. R., \& Pavithra, S. (2013). Electrodeposition of $\mathrm{Ni}-\mathrm{Co}-\mathrm{Sn}$ alloy from choline chloride-based deep eutectic solvent and characterization as cathode for hydrogen evolution in alkaline solution. International journal of hydrogen energy, 1-7. http://dx.doi.org/10.1016/j.ijhydene.2013.06.068

Wang, Q., Chen, B., Zhang, Q., \& Zhang, S. (2013). A Promising Electrolyte of Ionic Liquids for Aluminium Deposition, AlChe Annual Meeting Hilton Sanfrancisco Union Square.

Welch, B. J., \& Osteryoung, R. A. (1981). Electrochemical studies in low temperature molten salt systems containing alumnium chloride, J. Electroanal. Chem., 118, 456-466. http://dx.doi.org/10.1016/s0022-0728(81)80561-x

Zhang, L. P., Yu, X. J., Dong, Y. H., Li, D. G, Zhang, Y. L., \& Li, Z. F. (2010). Electrodeposition of aluminum on magnesium from ionic liquid (EMIM) $\mathrm{Br}-\mathrm{AlCl}_{3}$. Transactions of Nonferrous Metals Society of China, 20(1), 245-248. http://dx.doi.org /10.1016/S1003-6326(10)60048-9

\section{Copyrights}

Copyright for this article is retained by the author(s), with first publication rights granted to the journal.

This is an open-access article distributed under the terms and conditions of the Creative Commons Attribution license (http://creativecommons.org/licenses/by/3.0/). 